FCS2278

\title{
Importance of Youth Involvement in Sports ${ }^{1}$
}

Caroline Payne and Kate Fogarty ${ }^{2}$

\section{Overview}

Team sports provide children and youth with many opportunities to grow physically and socially, as well as emotionally. Moreover, physical activities with other children allow them to build social skills through peer interaction. Many parents are concerned about whether or not to allow their children to participate in team sports and, if so, at what age.

\section{At What Age Should Children Start Team Sports?}

Child development experts note that children become interested in team sports around ages 56 ("Physical milestones," 2003). Some early childhood educators feel that if children learn the importance of cooperating with their peers at a young age, they will be more socially ready for kindergarten and grade school (Nonis, 2005). However, adults must emphasize cooperation over competition in team sports, especially with young children. Adults who supervise and coach need to serve as examples of cooperation, not competition. Nor should they show favoritism to young children based on their demonstrated skills in sports (LandersPotts \& Grant, 1999). Children's (especially boys') motivation to participate in team sports moves from a focus on competition in early childhood to one on cooperation and friendship by the late elementary school years (Stern, Bradley, Prince, \& Stroh, 1990). Thus it's important to help young children advance developmentally to appreciate the cooperativeness of team sports.

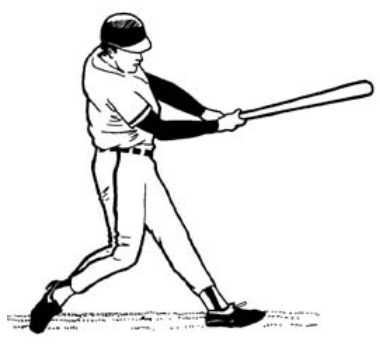

\section{Competition}

Team sports are useful for teaching youth many important skills. The first of these skills is competition. In today's world, we are surrounded by competition. Adults face competition when they are applying for and keeping jobs, whereas children face competition in academics and sports. Participating in competitive team sports at an early age gives children an opportunity to understand the

1. This document is FCS2278, one of a series of the Department of Family, Youth and Community Sciences, Florida Cooperative Extension Service, Institute of Food and Agricultural Sciences, University of Florida. First published: October 2007. Please visit the EDIS Web site at http://edis.ifas.ufl.edu.

2. Caroline Payne, graduate student, and Kate Fogarty, associate professor, Department of Family, Youth, and Community Sciences, Florida Cooperative Extension Service, Institute of Food and Agricultural Sciences, University of Florida, Gainesville, 32611. 
healthy aspects of competition in a friendly environment. Students of all ages who participate in sports have been found to cope better with competition in other areas of their life (Yan \& McCullagh, 2004). Still, highly competitive activity at young ages (5-7 years) for example, being part of teams that travel to competitions-may expose children to unhealthy values.

\section{Physical Benefits}

Team sports also help a child's physical wellbeing. Children who are actively involved in a sport are more likely to describe themselves as being in good physical health than students who do not participate in sports (Piko \& Keresztes, 2006). (There is limited research on the risk of injury for young children participating in team sports. See Spinks \& McClure, 2007.) Also, athletically active youth are more likely to be nutrition-conscious in their food choices than children who are not actively involved in a sport (Pyle, McQuivery, Brassington, \& Steiner, 2003).

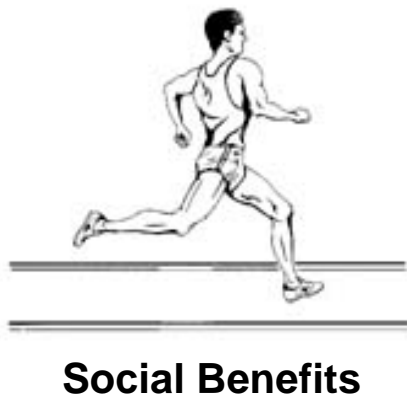

While the physical health benefits that sports provide youth are undoubtedly important, the social benefits may be what draw children to sports. Being able to spend time with their friends outside of school is more important to children than knowing they are physically active. Life skill gains through social interaction can be tremendous (Harrison \& Naraya, 2003). Social interaction in team sports teaches youth to: 1) Associate with their peers; 2) Solve conflict; and 3) Communicate effectively with their peers.

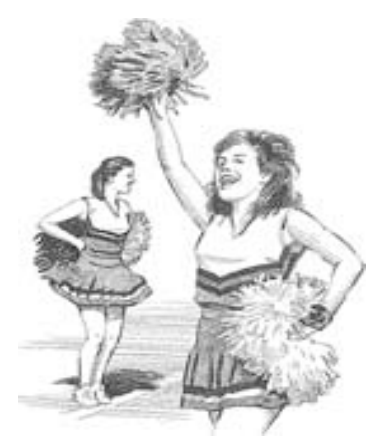

Emotional Benefits

Emotional growth is also important for youth. Sometimes, the emotional development of youth is hindered because of the physical and/or emotional absence of parents. Sports provide youth with opportunities to interact with a caring and supportive adult (Harrison \& Naraya, 2003). Adult support outside the family is a major protective factor for high-risk youth. The interaction a child has with his or her coach helps to improve self-esteem as well as lower the chance of depression (Harrison \& Naraya, 2003).

Sports team membership can also help increase a child's self-worth, especially when the emphasis is on group or team success, rather than individual achievement. Youth of all ages, including those in high school, are likely to receive an end-of-the-season trophy for participating in the team sport. Receiving a trophy with their teammates is intended to help youth feel a sense of accomplishment, teamwork, and recognition.

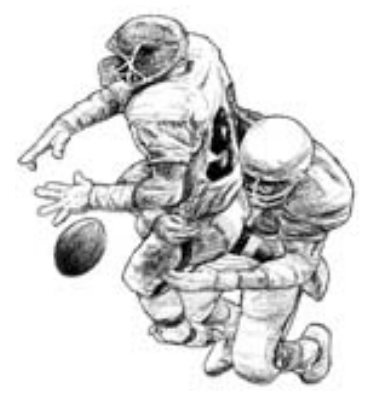




\section{Parental Involvement: "A Safe Zone"}

While sports can be positive and beneficial for children and teenagers, a parent's involvement in the child's sports participation can either be positive or negative. For a child who receives positive attention without pressure from the parent, this can be a good experience. However, a number of youth feel pressured by their parents to become college and professional athletes (Anderson, Funk, Elliott, \& Smith, 2003). For these children and teens, sports can become stressful and unenjoyable. While parental involvement is always encouraged, it must be done in a way that benefits the child. Children love to hear that their parents are sincerely proud of them. Youth involvement in sports provides the perfect opportunity for these types of interactions to take place (Anderson, Funk, Elliott, \& Smith, 2003).

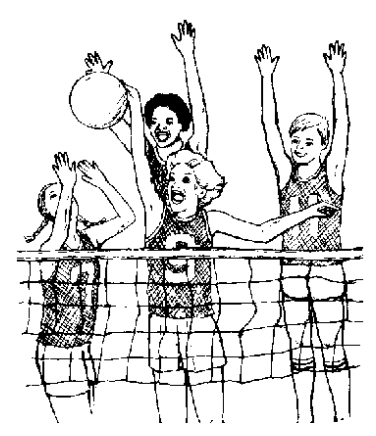

To encourage their child's healthy attitude toward team sports, parents should ensure that their children are not overly involved in sports and other extracurricular activities to the point that they feel it is an obligation and is no longer fun for them (Anderson, Funk, Elliott, \& Smith, 2003). When parents allow their children to be involved in excessive activities, children become overwhelmed and are likely to resent the activities and perform poorly (Piko \& Keresztes, 2006).

\section{Conclusion}

Sports provide numerous opportunities for children and teenagers to grow socially, emotionally, and physically. Furthermore, they also allow youth to learn and practice in a competitive environment. While sports may increase children's positive social interaction with adults and one another, they can also create stressful environments for children. For example, adults may place unrealistic pressure on their children to perform. Parents and children must find a balance in regard to how many extracurricular activities children participate in. Team sports participation can be an amazing tool that helps children grow and succeed in their everyday lives and in the future.

\section{References}

Anderson, J., Funk, J., Elliott, R. \& Smith, P. (2003). Parental support and pressure and children's extracurricular activities: relationships with amount of involvement and affective experience of participation. Journal of Applied Developmental Psychology, 24, 241-258.

Harrison, P., \& Naraya, G. (2003). Differences in behavior, psychological factors, and environmental factors associated with participation in school sports and other activities in adolescence. Journal of School Health, 73, 113.

Landers-Potts, M., \& Grant, L. (1999). Competitive climates, athletic skill, and children's status in after-school recreational sports programs. Social Psychology of Education, 2, 297-313.

Nonis, K. (2005). Kindergarten teachers' views about the importance of preschoolers' participation in sports in Singapore, Early Child Development \& Care, 175, 719-742.

Physical milestones. (2003). Scholastic Parent \& Child, 10(6), 40.

Piko, B., \& Keresztes, N. (2006). Physical activity, psychosocial health, and life goals among youth. Journal of Community Health, 31, 136-145.

Pyle, R., McQuivery, R., Brassington, G., \& Steiner, H. (2003). High school student athletes: Associations between intensity of participation and health factors. Clinical Pediatrics, 42, 697. 
Spinks, A., \& McClure, R.J. (2007),

Quantifying the risk of sports injury: A systematic review of activity-specific rates for children under 16 years of age, British Journal of Sports Medicine, 41, 548-557.

Stern, H. P., Bradley, R. H., Prince, M. T., \& Stroh, S. (1990). Young children in recreational sports: Participation motivation. Clinical

Pediatrics, 29, 89-

94.

Yan, J., \& McCullagh, P. (2004). Cultural influence on youth's motivation of participation in physical activity. Journal of Sport Behavior, 27, 378-390. 